\title{
In-Flight Calibrations of UFFO-Pathfinder
}

ípa, J.; Ahmad, S.; Barrillon, P.; Brandt, Søren; Budtz-Jørgensen, Carl; Castro-Tirado, A.J.; Chang, S.-H.; Chang, Y.-Y.; Chen, C.R.; Chen, P.

Total number of authors:

44

Published in:

E A S Publications Series

Link to article, DOI:

$10.1051 /$ eas/1361093

Publication date:

2013

Link back to DTU Orbit

Citation (APA):

ípa, J., Ahmad, S., Barrillon, P., Brandt, S., Budtz-Jørgensen, C., Castro-Tirado, A. J., Chang, S-H., Chang, YY., Chen, C. R., Chen, P., Choi, H. S., Choi, Y. J., Connell, P., Dagoret-Campagne, S., Eyles, C., Grossan, B., Huang, J. J., Huang, M-HA., Jeong, S., ... Yashin, I. (2013). In-Flight Calibrations of UFFO-Pathfinder. E A S Publications Series, 61, 579-581. https://doi.org/10.1051/eas/1361093

\section{General rights}

Copyright and moral rights for the publications made accessible in the public portal are retained by the authors and/or other copyright owners and it is a condition of accessing publications that users recognise and abide by the legal requirements associated with these rights.

- Users may download and print one copy of any publication from the public portal for the purpose of private study or research.

- You may not further distribute the material or use it for any profit-making activity or commercial gain

- You may freely distribute the URL identifying the publication in the public portal 


\title{
IN-FLIGHT CALIBRATIONS OF UFFO-PATHFINDER
}

J. Řípa ${ }^{1}$, S. Ahmad ${ }^{2}$, P. Barrillon ${ }^{2}$, S. Brandt ${ }^{3}$, C. Budtz-Jørgensen ${ }^{3}$, A.J. Castro-Tirado ${ }^{4}$, S.-H. Chang ${ }^{5}$, Y.-Y. Chang ${ }^{6}$, C.R. Chen ${ }^{5}$, P. Chen ${ }^{6}$, H.S. Choi ${ }^{7}$, Y.J. Choi ${ }^{8}$, P. Connell ${ }^{9}$, S. Dagoret-Campagne ${ }^{2}$, C. Eyles ${ }^{9}$, B. Grossan ${ }^{10}$, J.J. Huang ${ }^{6}$, M.-H.A. Huang ${ }^{11}$, S. Jeong ${ }^{12}$, A. Jung ${ }^{12}$, J.-E. Kim ${ }^{12}$, M.-B. Kim ${ }^{1}$, S.-W. Kim ${ }^{13}$, Y.-W. Kim ${ }^{1}$, A.S. Krasnov ${ }^{14}$, J. Lee ${ }^{1}$, H. Lim ${ }^{1}$, C.-Y. $\operatorname{Lin}^{5}$, E.V. Linder ${ }^{10}$, T.-C. Liu ${ }^{6}$, N. Lund ${ }^{3}$, K.W. $\mathrm{Min}^{8}$, G.-W. Na ${ }^{12}$, J.-W. Nam ${ }^{6}$, M.I. Panasyuk ${ }^{14}$, I.H. Park ${ }^{1}$, V. Reglero ${ }^{9}$, J.M. Rodrigo ${ }^{9}$, G.F. Smoot ${ }^{10}$, J.-E. Suh ${ }^{12}$, S. Svertilov ${ }^{14}$, N. Vedenkin ${ }^{14}$, M.-Z. Wang ${ }^{6}$, I. Yashin ${ }^{14}$ and others from the UFFO collaboration

\begin{abstract}
The Ultra-Fast Flash Observatory (UFFO), which will be launched onboard the Lomonosov spacecraft, contains two crucial instruments: UFFO Burst Alert \& Trigger Telescope (UBAT) for detection and localization of Gamma-Ray Bursts (GRBs) and the fastresponse Slewing Mirror Telescope (SMT) designed for the observation
\end{abstract}

\footnotetext{
${ }^{1}$ Sungkyunkwan University, Suwon, South Korea; e-mail: ripa.jakub@gmail.com

${ }^{2}$ Laboratoire de l'Accélérateur Linéaire, University of Paris-Sud 11, Orsay, France

3 Technical University of Denmark, Copenhagen, Denmark

${ }^{4}$ Instituto de Astrofsica de Andalucía, CSIC, Granada, Spain

5 National Space Organization, Taiwan

${ }^{6}$ LeCosPA, National Taiwan University, Taipei, Taiwan

${ }^{7}$ Korea Institute of Industrial Technology, Cheonan, South Korea

8 Department of Physics, Korea Advanced Institute of Science and Technology, Daejeon, South Korea

9 University of Valencia, Valencia, Spain

10 Institute for the Early Universe, Ewha Womans University, Seoul, South Korea

11 National United University, Miao-Li, Taiwan

12 Department of Physics, Ewha Womans University, Seoul, South Korea

13 Department of Astronomy, Yonsei University, Seoul, South Korea

14 SINP, Moscow State University, Moscow, Russia
} 
of the prompt optical/UV counterparts. Here we discuss the in-space calibrations of the UBAT detector and SMT telescope. After the launch, the observations of the standard X-ray sources such as pulsar in Crab nebula will provide data for necessary calibrations of UBAT. Several standard stars will be used for the photometric calibration of SMT. The celestial X-ray sources, e.g. X-ray binaries with bright optical sources in their close angular vicinity will serve for the crosscalibration of UBAT and SMT.

\section{Methods}

The UFFO-Pathfinder (Chen et al. 2011; Lim et al. 2012; Na et al. 2011; Park et al. 2012) consists of two scientific instruments. One is UBAT (Jung et al. 2011; Kim et al. 2012; Na et al. 2012; Rodrigo et al. 2012) for X-ray/gamma-ray observations of GRBs, and the second one is SMT (Jeong et al. 2011, 2012; Kim et al. 2011 ) of filed of view $17^{\prime} \times 17^{\prime}$ for optical/UV observations of GRB afterglows. UBAT provides SMT positional information of a burst and SMT afterwards slews to this location to start collecting the optical/UV data. After the launch the positional accuracy of SMT will be checked and compared with the positional accuracy of UBAT on the real sky sources. We searched for the brightest X-ray/gamma-ray sources in the sky (see Table 1), which have bright optical sources (in filter $\mathrm{V}$ and/or $\mathrm{B}<10-5 \mathrm{mag}$ ) in close angular vicinity $\sim 5$ arcmin and we intend to use them for UBAT-SMT positional cross-calibration and check up of the system (see Fig. 1).

By observing the Crab pulsar (Kirsch et al. 2005) we plan to carry out flux and positional accuracy calibrations of UBAT itself. After the launch we plan to take observations of several standard photometric stars in order to perform photometric calibration of SMT.

Table 1. An example of the brightest celestial X-ray sources, here the three brightest sources in the energy range 20-100 keV from the Fourth IBIS/ISGRI Soft Gamma-Ray Survey Catalog (Bird et al. 2010), which is the all sky catalogue compiled from the observations by the INTEGRAL satellite. Objects such as radio pulsars, high mass X-ray binaries (HMXRB) etc. will be used for cross-calibrations of SMT and UBAT.

\begin{tabular}{|c|c|c|c|c|}
\hline Object & $\begin{array}{c}\text { RA } \\
(\operatorname{deg})\end{array}$ & $\begin{array}{c}\text { dec } \\
(\operatorname{deg})\end{array}$ & $\begin{array}{c}\text { Flux at } 20-100 \mathrm{keV} \\
\left(\mathrm{ph} . \mathrm{s}^{-1} \cdot \mathrm{cm}^{-2}\right)\end{array}$ & Type \\
\hline Crab & 83.63 & 22.02 & 0.27 & Radio Pulsar \\
\hline Cyg X-1 & 299.60 & 35.20 & 0.21 & HMXRB \\
\hline $4 \mathrm{U} 1700-377$ & 255.99 & -37.85 & 0.05 & HMXRB \\
\hline
\end{tabular}




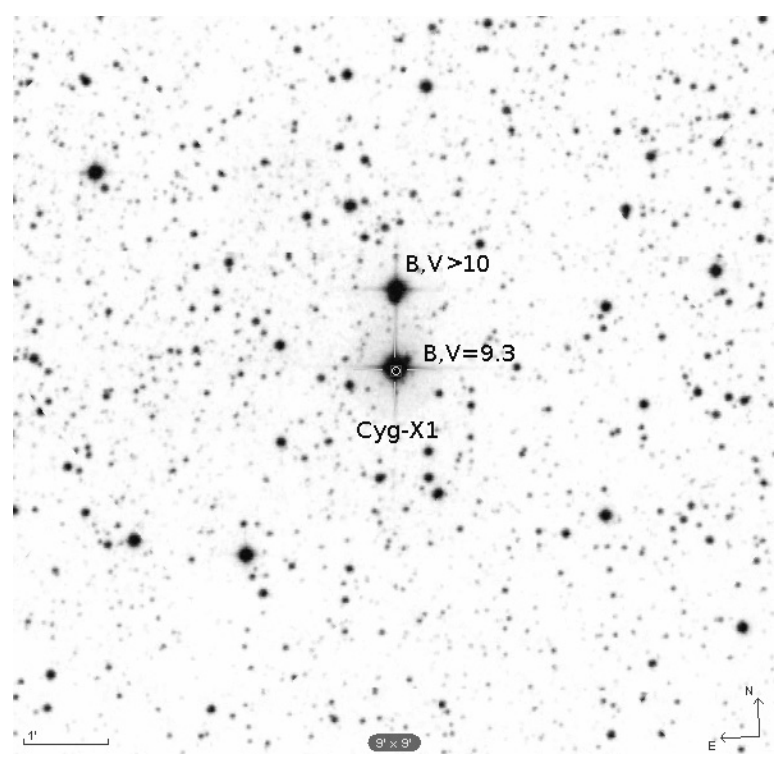

Fig. 1. An example of a bright celestial X-ray source (X-ray binary Cyg-X1) which is also bright in the optical range and also has a bright optical source, star V1674 Cyg, at a distance of 54 arcsec. X-ray source like this can be used for cross-calibration of SMT and UBAT.

This study was supported by Creative Research Initiatives (RCMST) of MEST/NRF.

\section{References}

Bird, A.J., Bazzano, A., Bassani, L., et al., 2010, ApJS, 186, 1

Chen, P., Ahmad, S., Ahn, K., et al., 2011, Proc. 32nd Int. Cosmic Ray Conf., 8, 240

Jeong, S., Ahn, K., Nam, J., et al., 2011, Proc. 32nd Int. Cosmic Ray Conf., 8, 238

Jeong, S., Ahmad, S., Barrillon, P., et al., 2012, Proc. SPIE, 8443, id. 84432S

Jung, A., Ahmad, S., Ahn, K., et al., 2011, Proc. 32nd Int. Cosmic Ray Conf., 8, 230

Kim, J.E., Lim, H., Jung, A., et al., 2011, Proc. 32nd Int. Cosmic Ray Conf., 8, 234

Kim, J.E., Ahmad, S., Barrillon, P., et al., 2012, Proc. SPIE, 8443, id. 84432V

Kirsch, M.G., Briel, U.G., Burrows, D., et al., 2005, Proc. SPIE, 5898, 22

Lim, H., Ahmad, S., Barrillon, P., et al., 2012, Proc. Int. Astron. Union, 279, 349

Na, G.W., Ahn, K., Choi, H.S., et al., 2011, Proc. 32nd Int. Cosmic Ray Conf., 8, 222

Na, G.W., Ahmad, S., Barrillon, P., et al., 2012, Proc. SPIE, 8443, id. 84432T

Park, I.H., Ahmad, S., Barrillon, P., et al., 2012, Proc. SPIE, 8443, id. 84430I

Rodrigo, J.M., Macián, J.M., Biosca, J.T., et al., 2012, Mem. Soc. Astron. Ital., 83, 370 